\title{
Management and retrospective analysis of pelvic ramus tumors and tumor-like lesions: Evaluation with 31 cases
}

\author{
Recep Öztürk, MD (D), Coşkun Ulucaköy, MD (D), İsmail Burak Atalay, MD®D, \\ Aliekber Yapar, MD (D), Yaman Karakoç, MD (D) \\ Department of Orthopedics and Traumatology, Dr. Abdurrahman Yurtaslan Ankara Oncology Training and Research Hospital, Ankara, Turkey
}

Primary benign and malignant bone tumors and metastases can be located in pelvic ramus. ${ }^{[1-4]}$ In addition, non-tumor benign processes can be confused with tumor lesions. ${ }^{[5-7]}$ Considering all tumors that settle in the ramus, although there are no data about the incidence of ramus tumors in the literature, chondrosarcoma (CS) is the most common tumor when the case reports are examined. ${ }^{[3,4,8-10]}$ Also, the most common benign tumor is aneurysmal bone cyst $(\mathrm{ABC}) .^{[11-14]}$ Ramus tumors can be seen in a wide range of ages. ${ }^{[10,15]}$ Patients usually present with symptoms of inguinal pain, swelling, or both. $[2,15,16]$ Examination findings usually include a mass or sensitivity in that area. Some patients are detected by coincidental lesions on radiographs. ${ }^{[4,17,18]}$ In almost all lesions, firstly, the lesion is detected by direct radiographs and further examinations are performed such as magnetic resonance imaging (MRI) or computed tomography. The treatment of tumors located in ramus varies according to tumor type. Follow-up, excision/curettage + adjuvant therapies or en-bloc resection can be performed in benign tumors..$^{[2,4,6,15,16,19]}$ In malignant tumors and metastases, wide resection (en-bloc resection of

Received: December 09, 2019

Accepted: February 05, 2020

Published online: March 26, 2020

Correspondence: Recep Öztürk, MD. Dr. Abdurrahman Yurtaslan Ankara Onkoloji Eğitim ve Araştırma Hastanesi Ortopedi ve Travmatoloji Kliniği, 06200 Yenimahalle, Ankara, Türkiye.

E-mail: ozturk_recep@windowslive.com

Doi: 10.5606/ehc. 2020.72762

Citation: Öztürk R, Ulucaköy C, Atalay IB, Yapar A, Karakoç Y. Management and retrospective analysis of pelvic ramus tumors and tumor-like lesions: Evaluation with 31 cases. Jt Dis Relat Surg 2020;31(2):184-192.

\section{ABSTRACT}

Objectives: This study aims to investigate the characterization, treatment approaches, and follow-up results of tumors and tumor-like lesions located in the pelvic ramus.

Patients and methods: Thirty-one patients (9 males, 22 females; mean age 48.9 years; range, 7 to 79 years) with benign and malignant tumors or tumor-like lesions in the pelvic ramus region treated and followed-up in our clinic between January 2005 and January 2019 were evaluated retrospectively. Surgical procedures were performed with anterior approach or inner-thigh approach. Twelve patients were diagnosed with malignant tumors, 12 patients with benign tumors, and seven patients with tumor-like lesions.

Results: Seventeen patients who underwent surgical treatment were followed-up for a mean period of 61.7 months. The diameters of benign and malignant tumors were similar $(\mathrm{p}=0.425)$. Of all lesions, $64.5 \%$ were located in the pubis. Ischium location was significantly higher in patients with malignant lesions than tumor-like lesions. The most common complication was diffuse subcutaneous edema in the inguinal region and thigh (8.3\%).

Conclusion: There are many different tumoral lesions in the pelvic ramus. Pelvic ramus tumors tend to settle more frequently in pubic ramus, whereas ramus ischium tumors are more likely to be malignant. In addition, the diagnosis of insufficiency fracture should be considered primarily in pathologic fractures of pubic ramus in females over 50 years of age. In the postoperative follow-up of pelvic ramus tumors, diffuse edema may occur even if there is no intraoperative vascular damage.

Keywords: Bone tumor, ramus ischium, pubic ramus, surgical outcomes.

the involved ramus section) and/or combinations of non-surgical medical treatments such as chemotherapy and radiotherapy are performed according to the type and stage of the tumor. . $^{[3,4,8-10,20]}$

Tumors of illiopubic or ischiopubic ramus are very rare. Due to this, the literature data are very limited. Moreover, the surgical approach to this deep part of the pelvis and the surgical procedures performed in this region are quite difficult due to their proximity to some important ligaments and vital neurovascular 

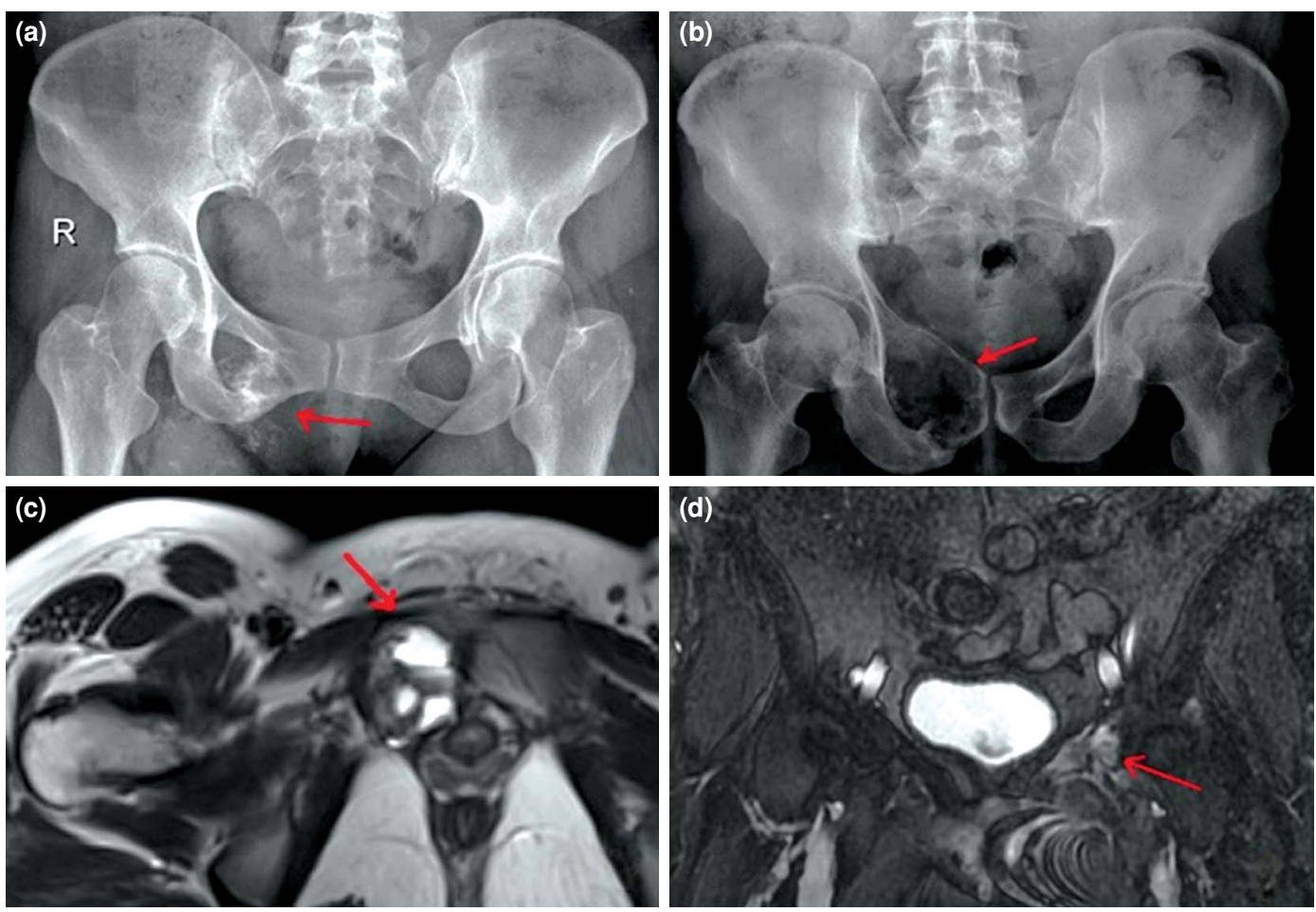

FIGURE 1. (a) Direct radiography of chondrosarcoma in right ramus ischium. (b) Direct X-ray of plasmacytoma, including right superior and inferior pubic ramus, expanding in the bone, causing cortical thinning and destruction in places. (c) Axial T2 sequence magnetic resonance image of a simple bone cyst in right pubic ramus. (d) $X$-ray of left pubic ramus insufficiency fracture.

structures. ${ }^{[3,4,21]}$ Our hypothesis was that, in lesions detected in pelvic ramus, the possible diagnosis may include a wide range of benign and malignant tumors and tumor-like lesions. Therefore, in this study, we aimed to investigate the characterization, treatment approaches, and follow-up results of tumors and tumor-like lesions located in the pelvic ramus.

\section{PATIENTS AND METHODS}

In this study, we retrospectively evaluated patients who underwent surgical or medical treatment due to tumors or tumor-like lesions in the pelvic ramus in the orthopedic oncology clinic of Dr. Abdurrahman Yurtaslan Ankara Oncology Training and Research Hospital between January 2005 and January 2019. A total of 39 patients were found. Inclusion criteria were patients with primary/metastatic tumors or tumor-like lesions in the ramus ischium/pubic ramus and histopathological diagnosis of this lesion. Histopathological diagnosis was established by fine needle aspiration biopsy or incisional biopsy. Exclusion criteria were the presence of a lesion in the acetabulum or ilium requiring additional surgery to ramus tumor surgery. According to these criteria, a total of 31 patients ( 9 males, 22 females; mean age 48.9 years; range, 7 to 79 years) were included. The study protocol was approved by the Dr. Abdurrahman Yurtaslan Ankara Oncology Training and Research Hospital Medical Specialization Training Board. A written informed consent was obtained from each patient. The study was conducted in accordance with the principles of the Declaration of Helsinki.

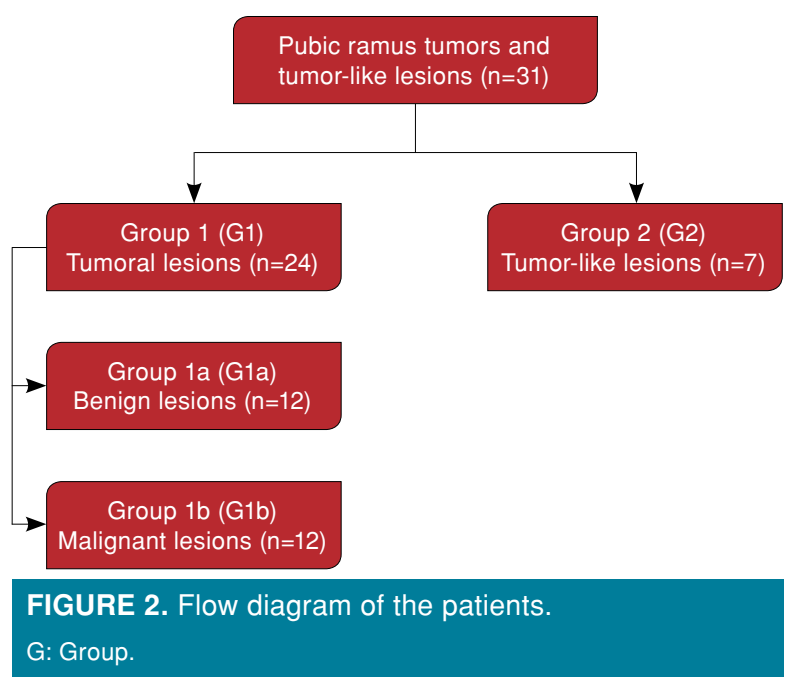


Long-term clinical outcomes and complications of surgical treatment were reviewed. Seventeen patients were treated surgically $(84.8 \%)$ while 14 underwent only biopsy and non-surgical methods. All patients with mass lesion in pelvic ramus had pelvic radiography, lower abdomen MRI or tomography (Figure 1). In addition, patients with malignant tumors had scintigraphy, upper abdomen tomography, and lung tomography.
Twenty-four patients had tumors: 12 had benign tumors while 12 had malignant tumors (Figure 2). The diagnoses of the patients were given in Table I. Histopathological diagnoses in patients in the tumor-like lesions group were osteoporotic fracture callus (insufficiency fracture), bone lamellae, fibrosis, bleeding bone tissues showing reactive regenerative changes or reactive bone formation.

\begin{tabular}{|c|c|c|c|c|c|c|c|c|c|}
\hline \multicolumn{10}{|c|}{$\begin{array}{l}\text { TABLE I } \\
\text { Patients' demographic data, diagnosis, treatment, and treatment results }\end{array}$} \\
\hline Order & $\begin{array}{l}\text { Age/ } \\
\text { Gender }\end{array}$ & Side & Localization & $\begin{array}{l}\text { Lesion } \\
\text { type }\end{array}$ & Diagnosis & Treatment & $\begin{array}{l}\text { Follow-up* } \\
\text { (months) }\end{array}$ & Complication* & $\begin{array}{l}\text { Relaps* } \\
\text { (months) }\end{array}$ \\
\hline 1 & $19 / \mathrm{M}$ & $\mathrm{L}$ & $\mathrm{P}$ & $\mathrm{B}$ & $\mathrm{ABC}$ & $\mathrm{SAE}+\mathrm{C}+\mathrm{HSB}+\mathrm{TCC}$ & 61 & $\mathrm{DE}$ & \\
\hline 2 & $13 / F$ & $\mathrm{~L}$ & $\mathrm{P}$ & B & $\mathrm{ABC}$ & $\mathrm{SAE}+\mathrm{C}+\mathrm{HSB}+\mathrm{TCC}$ & 50 & & \\
\hline 3 & $16 / F$ & $L$ & 1 & B & SBC & $\mathrm{C}+\mathrm{HSB}+\mathrm{TCC}$ & 31 & & \\
\hline 4 & $17 / F$ & $\mathrm{R}$ & $P$ & B & SBC & $\mathrm{C}+\mathrm{HSB}+\mathrm{TCC}$ & 24 & & \\
\hline 5 & $45 / F$ & $\mathrm{R}$ & 1 & B & GCT & $\mathrm{C}+\mathrm{HSB}+\mathrm{TCC}$ & 104 & & \\
\hline 6 & $42 / F$ & $\mathrm{R}$ & $\mathrm{I}+\mathrm{P}$ & $B$ & GCT & $\mathrm{C}+\mathrm{HSB}+\mathrm{TCC}+\mathrm{G}$ & 132 & & \\
\hline 7 & $79 / F$ & $L$ & $\mathrm{P}$ & $B$ & ENC & $\mathrm{C}+\mathrm{HSB}+\mathrm{TCC}$ & 97 & & \\
\hline 8 & $46 / \mathrm{M}$ & $\mathrm{R}$ & $\mathrm{P}$ & $B$ & FD & $\mathrm{C}+\mathrm{HSB}+\mathrm{TCC}+\mathrm{G}$ & 102 & & \\
\hline 9 & $43 / F$ & $\mathrm{~L}$ & $P$ & B & CMF & $\mathrm{C}+\mathrm{HSB}+\mathrm{TCC}+\mathrm{G}$ & 46 & & \\
\hline 10 & $6 / \mathrm{M}$ & $\mathrm{L}$ & $P$ & B & $\mathrm{LCH}$ & $\mathrm{C}+\mathrm{HSB}+\mathrm{TCC}+\mathrm{LNE}$ & 43 & & \\
\hline 11 & $35 / \mathrm{M}$ & $\mathrm{R}$ & $\mathrm{P}$ & B & Oc & Marginal excision & 43 & & \\
\hline 12 & $78 / F$ & $\mathrm{~L}$ & 1 & B & OF & $\mathrm{C}+\mathrm{HSB}+\mathrm{TCC}$ & 98 & & \\
\hline 13 & $14 / \mathrm{M}$ & $\mathrm{L}$ & $\mathrm{P}$ & M & EWS & Wide excision & 14 & & \\
\hline 14 & $65 / F$ & $L$ & I & $M$ & CS & Wide excision & 12 & & \\
\hline 15 & 33/M & $L$ & $\mathrm{P}$ & $M$ & CS & Wide excision & 77 & DE & $29^{\text {th }}$ \\
\hline 16 & $36 / \mathrm{M}$ & $L$ & 1 & M & CS & Wide excision & 51 & & \\
\hline 17 & $44 / F$ & $\mathrm{R}$ & 1 & M & CS & Wide excision & 37 & WHP & \\
\hline 18 & $72 / F$ & $\mathrm{~L}$ & 1 & $M$ & MET & Medical & - & - & - \\
\hline 19 & $75 / F$ & $\mathrm{R}$ & $\mathrm{P}$ & M & Lym & Medical & - & - & - \\
\hline 20 & $57 / \mathrm{M}$ & $\mathrm{R}$ & $\mathrm{P}$ & M & MM & Medical & - & - & - \\
\hline 21 & $59 / F$ & $\mathrm{R}$ & $P$ & M & MM & Medical & - & - & - \\
\hline 22 & $70 / F$ & $\mathrm{R}$ & $P$ & M & MM & Medical & - & - & - \\
\hline 23 & $64 / M$ & $L$ & $\mathrm{P}$ & M & MET & Medical & - & - & - \\
\hline 24 & $25 / F$ & $\mathrm{R}$ & I & $\mathrm{M}$ & $\mathrm{CS}$ & Medical & - & - & - \\
\hline 25 & $73 / F$ & $\mathrm{R}$ & $\mathrm{P}$ & TLL & TLL & Medical & - & - & - \\
\hline 26 & $52 / F$ & $L$ & $\mathrm{P}$ & TLL & TLL & Medical & - & - & - \\
\hline 27 & $65 / F$ & $\mathrm{R}$ & $\mathrm{I}+\mathrm{P}$ & TLL & TLL & Medical & - & - & - \\
\hline 28 & $77 / F$ & $\mathrm{R}$ & $\mathrm{P}$ & TLL & TLL & Medical & - & - & - \\
\hline 29 & $49 / F$ & $\mathrm{R}$ & $\mathrm{P}$ & TLL & TLL & Medical & - & - & - \\
\hline 30 & $73 / F$ & $\mathrm{R}$ & $\mathrm{I}+\mathrm{P}$ & TLL & TLL & Medical & - & - & - \\
\hline 31 & $76 / F$ & $L$ & $\mathrm{P}$ & TLL & TLL & Medical & - & - & - \\
\hline $\begin{array}{l}{ }^{*} \text { In oper } \\
\text { burr; TC } \\
\text { Enchond } \\
\text { Ossifyin } \\
\text { myelome }\end{array}$ & $\begin{array}{l}\text { ated patients } \\
\text { : Thermo- or } \\
\text { roma; FD: Fit } \\
\text { fibroma; M: } \\
\text {; TLL: Tumor- }\end{array}$ & M: Male & $\begin{array}{l}\text {; L: Left; P: Pubis } \\
\text { auterization; F: Fe } \\
\text { plasia; CMF: Chor } \\
\text { tt; EWS: Ewing's s } \\
\text { n. }\end{array}$ & $\begin{array}{l}\text { Benign; } \\
\text { le; } \mathrm{DE}: \mathrm{Di} \\
\text { omyxoid } \mathrm{f} \\
\text { oma; CS: }\end{array}$ & $\begin{array}{l}\text { C: Aneurysma } \\
\text { se edema; I: Is } \\
\text { oma; LCH: Lar } \\
\text { ondrosarcome }\end{array}$ & $\begin{array}{l}\text { one cyst; SAE: Selective } \\
\text { ium; SBC: Simple bone c) } \\
\text { rhans cell histiocytosis; } \\
\text { VHP: Wound healing prob }\end{array}$ & $\begin{array}{l}\text { rial embolizat } \\
\text { R: Right; GCT } \\
\text { Lymph node } \\
\text {; MET: Metast }\end{array}$ & $\begin{array}{l}\text {; C: Curettage; HS } \\
\text { iant cell tumor; G: } \\
\text { cision; Oc: Osteoch } \\
\text { is; Lym: Lymphoma }\end{array}$ & $\begin{array}{l}\text { High-speec } \\
\text { rafting; ENC } \\
\text { ndroma; OF } \\
\text { MM: Multiple }\end{array}$ \\
\hline
\end{tabular}


In patients who underwent surgery, the surgical planning was decided by localization of the lesion, scope, and histopathology. All patients who underwent surgical treatment were followed-up for at least one year.

Surgical treatment was not considered in three patients with multiple myeloma, two patients with metastasis to ramus, and one patient with extensive metastatic giant CS. These patients were consulted to hematology, medical oncology, and radiation oncology departments for medical treatment plan and follow-up. Eight patients with tumor-like lesions did not undergo additional surgery; they were followedup orthopedically and consulted to the physical and endocrine departments for the cause, treatment, and follow-up of the insufficiency fracture.

Two different surgical approaches were used depending on the location of the lesion. Urinary catheterization was performed in both approaches. In the anterior approach, a longitudinal incision was performed along the pubic ramus from the lateral side of the pubic tubercle. The ramus was reached with the femoral artery-vein package remaining lateral, the inguinal ligament remaining inferior, the bladder remaining superior, and the pubic tubercle medial (Figure 3a, b). The distal insertion of the rectus muscle was retracted to the superior. In the necessary cases, the retrosymphyseal region was examined in a blunt manner with the help of fingers, without damaging the bladder or prostatic venous plexus. Also, in the necessary cases, the incision was enlarged at both ends, and care was taken to protect the spermatic cord and round ligament. In the inner-thigh approach, a longitudinal incision was performed through the inferior ischial ramus to the ischial tuberosity of the patient lying in the lithotomy position. ${ }^{[4]}$ Subcutaneous tissue and deep fascia were incised. The adductor muscle group and the obturator externus muscle were separated subperiosteally by sharp or blunt dissection from the sites of attachment, thus exposing the lateral margin of the inferior pubic ramus. Surgery was completed by preserving the vessels, nerves, and pelvic organs (Figure 3c).

\section{Statistical analysis}

Statistical analysis was performed using the IBM SPSS version 22.0 software (IBM Corp., Armonk, NY, USA). Categorical variables were given as numbers and percentages while continuous variables were presented with mean \pm standard deviation and median (min-max value) for descriptive analyses. Chi-square tests were used for comparison of categorical variables between groups. The conformity of continuous variables to normal distribution was evaluated using visual (histogram and probability graphs) and analytical methods (KolmogorovSmirnov/Shapiro-Wilk tests). Normality analysis revealed that all data sets were not distributed normally. Mann-Whitney $U$ test was used for comparison of data sets which were not normally distributed for the variables. Spearman's correlation was used to test the association between the diameters and patients' ages. $\mathrm{P}<0.05$ was considered statistically significant.
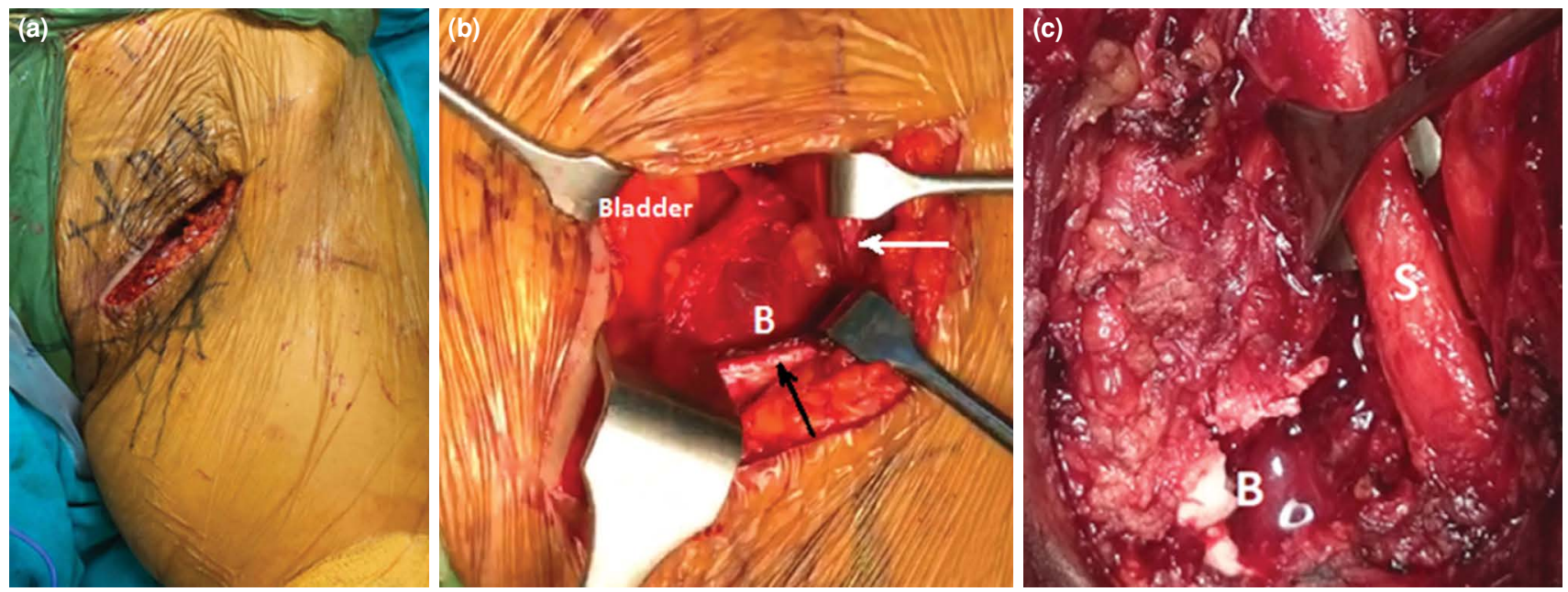

FIGURE 3. Surgical approaches. (a, b) Skin incision in anterior approach and access to pubic ramus through fascia. (c) Pathological fracture of pubic ramus in inner-thigh approach and sciatic nerve in neighborhood.

White arrow: Femoral artery vein pack; Black arrow: Inguinal ligament; B: Bone; S: Sciatic nerve. 


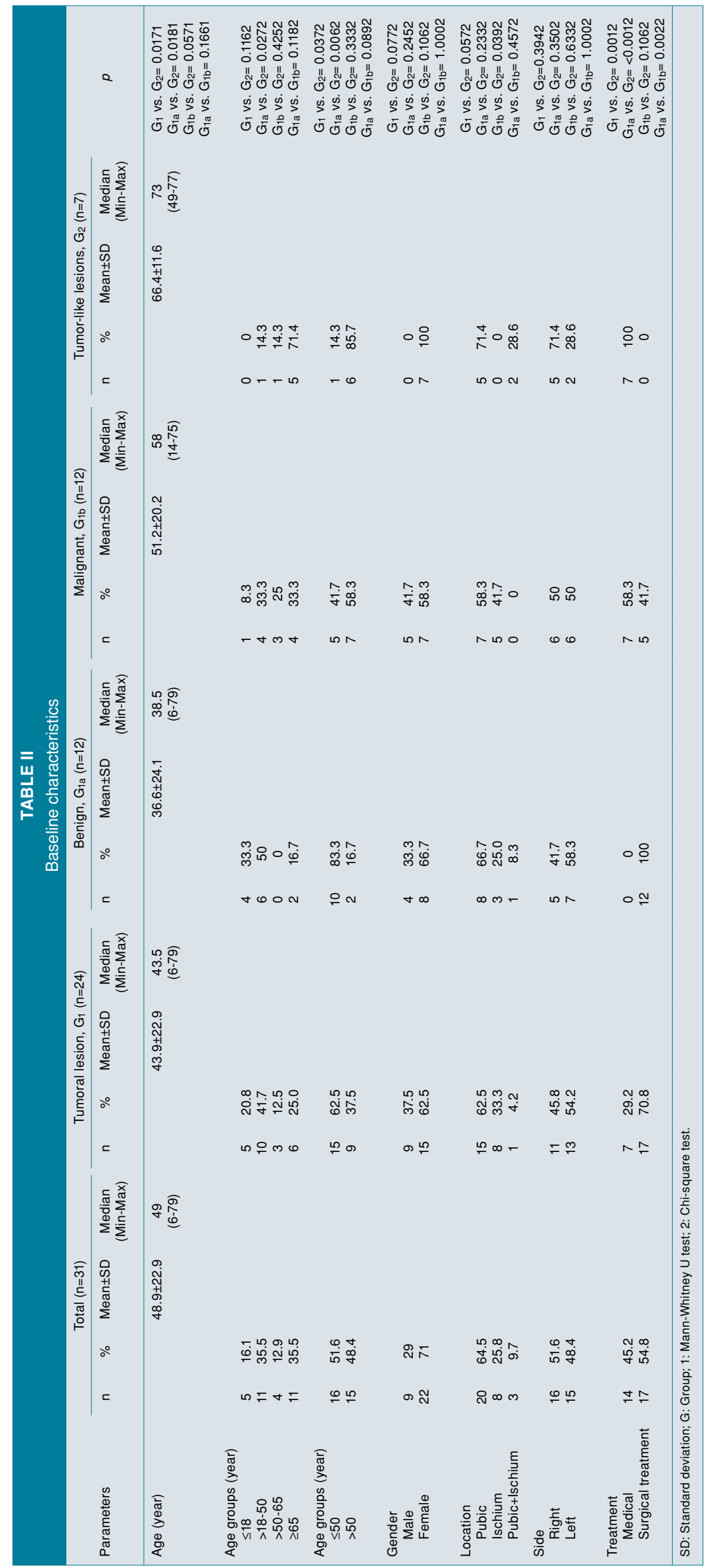




\section{RESULTS}

A screening of the patients who underwent surgical intervention for ramus tumor or tumor-like lesion from the oncologic orthopedic clinic database of our hospital revealed 39 patients. Eight patients were excluded because of the involvement of the acetabular medal along with ramus requiring additional acetabular surgery. Diagnoses of the excluded patients included CS $(n=2)$, giant cell tumor (GCT), bladder cancer metastasis, paracaval paraganglioma metastasis, Ewing's sarcoma (EWS), desmoid tumor, and primary unknown adenocarcinoma metastasis.

Of the 31 patients, 24 had tumoral lesions while seven had tumor-like lesions (Table I). Fifteen patients $(48.4 \%)$ were older than 50 years of age.

The main complaints of the patients were pain and swelling or coexistence. One patient presented with inguinal pain and swelling in addition to hip movement restriction, while one patient presented with only urinary incontinence symptoms. The duration of preoperative symptoms ranged from 1 to 48 months. In addition, the lesion was found incidentally in three patients, two of whom were detected on direct radiographs after a traffic accident, and one of three was detected in staging studies of other malignancies.

Table II presents some characteristics of the patients according to the diagnostic groups. Age values of the group with tumoral lesions were significantly lower than those with tumor-like lesions $(p=0.017)$. According to this, $62.5 \%$ of the tumor lesions were in those aged under 50 years, while $14.3 \%$ of patients with tumor-like lesions were aged under 50 years $(p=0.037)$. Gender and lesion distribution of the lesions were similar in the diagnostic groups ( $p>0.05)$. While $64.5 \%$ of all lesions $(n=20)$ were located in the pubis, eight were located in the ischium, and three were located in the pubis-ischium. Pubis locations of tumor-like lesions were significantly higher than those of malignant tumors, whereas ischial location of those with malignant lesions was significantly higher than that of tumor-like lesions $(\mathrm{p}=0.039)$.

No recurrence or complication was observed in any of the five patients who had curettage + highspeed burr + thermo- or chemocauterization and one patient who had marginal excision. Curettage + high-speed burr + thermo- or chemocauterization + grafting treatment was applied to three patients. A 42-year-old female patient with GCT had
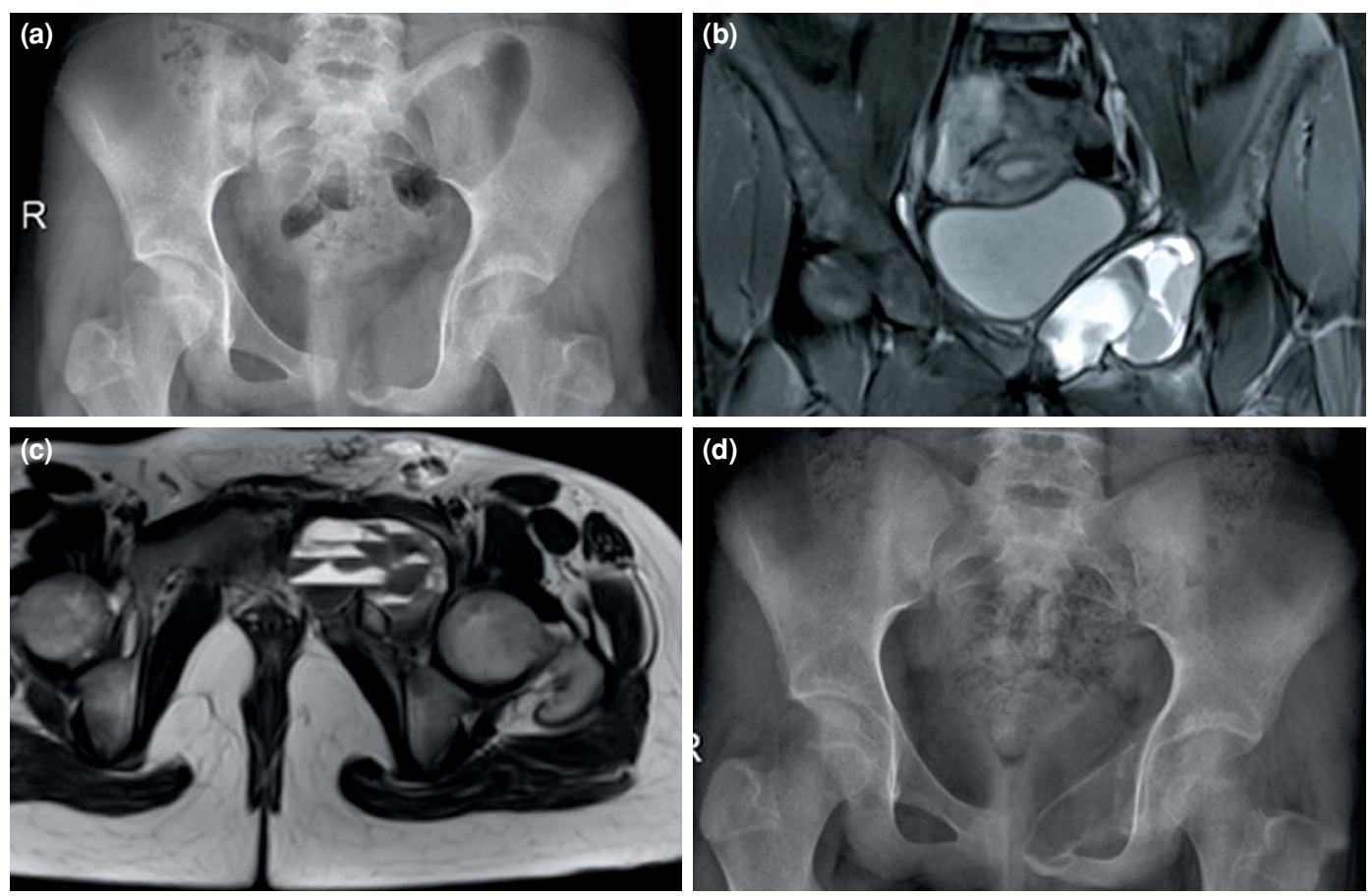

FIGURE 4. (a) Aneurysmal bone cyst with an expansion of approximately $66 \times 60 \mathrm{~mm}$ in left pubic ramus. (b, c) Aneurysmal bone cyst with lobulated contoured smooth bounded multiloculated levels on coronal and sagittal magnetic resonance imaging sections, respectively. (d) Postoperative $13^{\text {th }}$ month direct X-ray. 

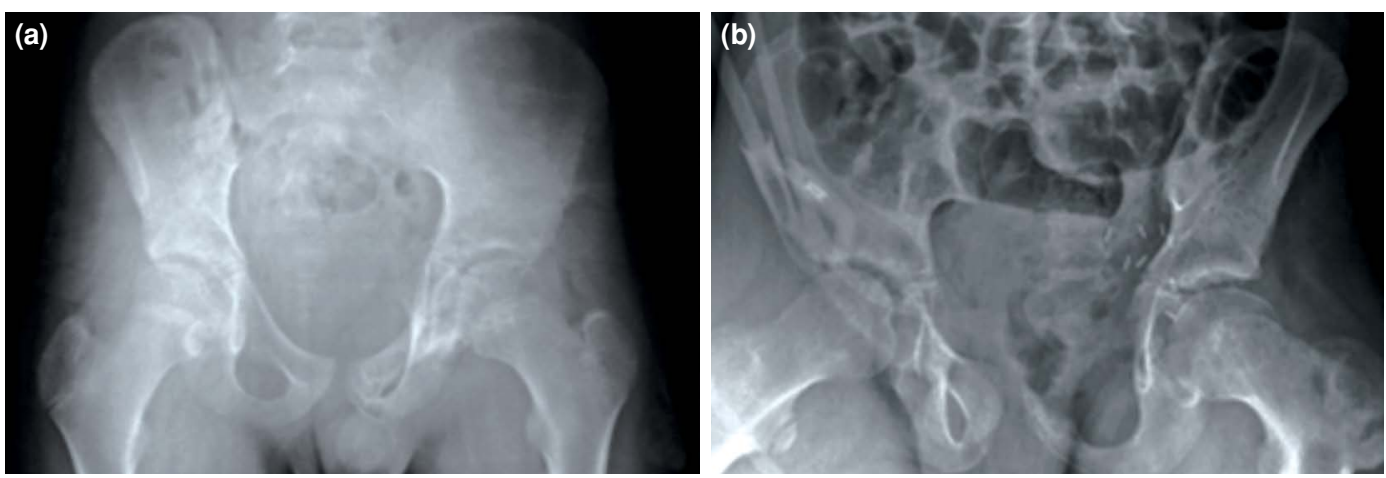

FIGURE 5. (a) Preoperative X-ray image of Ewing's sarcoma in left pubic ramus after neoadjuvant chemotherapy of a 14-year-old male patient. (b) Postoperative X-ray image.

a $7 \times 15 \times 6 \mathrm{~mm}$ nodular lesion in the right lower lobe of the lung at the time of diagnosis. Medical oncology and thoracic surgery were recommended without treatment. No progression was detected in the nodular lesion during follow-up. No recurrence or complication was observed in any of the three patients. Two patients diagnosed with $\mathrm{ABC}$ underwent preoperative selective arterial embolization + curettage + high-speed burr + thermo- or chemocauterization (Figure 4). On the $30^{\text {th }}$ day, one of the patients had subcutaneous edema in the inguinal region and incision line. Although this edema regressed significantly over time, there was a slight edema-swelling that did not disturb the patient at $61^{\text {st }}$ month follow-up. No recurrence was detected in any of the two patients. The patient with Langerhans cell histiocytosis $(\mathrm{LCH})$ underwent curettage + high-speed burr + thermo- chemocauterization and the same-side lymph node was excised in the same session. The histopathological examination of the resected lymph nodes, approximately $5.5 \mathrm{~cm}$ in size, was consistent with metastasis. Chemotherapy (vinblastine) was applied to this tumor whose behavior was considered unpredictable by the pediatric oncology department. The patient is still under follow-up at $43^{\text {rd }}$ month without any recurrence or complication (Table I).
Wide excision was performed in five patients. The patient with EWS was treated with neoadjuvant and adjuvant chemotherapy (Figure 5). The patient who had recurrence + lung metastasis in the $12^{\text {th }}$ postoperative month died in the $14^{\text {th }}$ month follow-up.

The first of the four patients with CS had a history of chondroma excision from the same site 62 months before. This patient also had a woundhealing problem in the postoperative period. In this patient, the wound healed completely in four months of follow-up. The second patient had hereditary multiple exocytosis. In the $12^{\text {th }}$ month follow-up, biopsy of the rapidly growing lesion in the cervical region was presented as grade I CS and extensive resection was performed. The third patient died due to accompanying cervix cancer in 12 months of follow-up. Recurrence occurred in the $29^{\text {th }}$ month of follow-up after extensive resection of low grade peripheral CS of the fourth patient. Histopathological examination of the resection material revealed that the tumor was grade II. Two more relapses were observed after nine months and 26 months, and both underwent extensive resection. The patient is still under follow-up without metastasis. In all operations of the patient, diffuse subcutaneous edema including inguinal region and proximal thigh was observed after months of regression.

\begin{tabular}{|c|c|c|c|c|c|c|}
\hline \multicolumn{7}{|c|}{$\begin{array}{l}\text { TABLE III } \\
\text { Correlation between age and diameter in surgical patients }\end{array}$} \\
\hline & \multicolumn{6}{|c|}{ Diameter (cm) } \\
\hline & \multicolumn{2}{|c|}{ Total $(n=17)$} & \multicolumn{2}{|c|}{ Benign $(n=12)$} & \multicolumn{2}{|c|}{ Malign $(n=5)$} \\
\hline & $r$ & $p$ & $r$ & $p$ & $r$ & $p$ \\
\hline Age & -0.058 & 0.825 & 0.152 & 0.638 & -0.359 & 0.553 \\
\hline
\end{tabular}




\begin{tabular}{|c|c|c|c|c|c|c|c|c|c|c|}
\hline \multirow[b]{3}{*}{ Parameters } & \multicolumn{9}{|c|}{$\begin{array}{c}\text { TABLE IV } \\
\text { Evaluation of tumoral lesion groups }\end{array}$} & \multirow[b]{3}{*}{$p$} \\
\hline & \multicolumn{3}{|c|}{ Total $(n=17)$} & \multicolumn{3}{|c|}{ Benign $(n=12)$} & \multicolumn{3}{|c|}{ Malign $(n=5)^{*}$} & \\
\hline & Mean $\pm S D$ & Median & Min-Max & Mean $\pm S D$ & Median & Min-Max & Mean \pm SD & Median & Min-Max & \\
\hline Diameter (cm) & $6.9 \pm 3.2$ & 7 & $2-13$ & $6.6 \pm 2.9$ & 6 & $3-12$ & $7.6 \pm 3.9$ & 8 & $2-13$ & $0.425 \dagger$ \\
\hline Follow-up time (month) & $61.8 \pm 33.7$ & 50 & $12-132$ & $69.3 \pm 35.3$ & 55.5 & 24-132 & $43.8 \pm 23.5$ & 42 & $12-77$ & $0.170 \dagger$ \\
\hline
\end{tabular}

Of the patients, $45.2 \%$ received medical treatment while $54.8 \%$ received surgical treatment. While $70.8 \%$ of patients with tumor lesions had surgical treatment, all patients with tumor-like lesions received only medical treatment $(\mathrm{p}=0.001)$. All patients with benign tumors had surgical treatment whereas $41.7 \%$ of patients with malignant tumors had surgical treatment $(\mathrm{p}=0.002)$ (Table II).

A total of 17 patients who underwent surgical treatment were followed-up for an average of 61.7 months (range, 12 to 132 months). No significant relationship was found between tumor diameter and age $(p>0.05)$ (Table III). The diameter and follow-up time of benign and malignant tumor lesions were similar ( $\mathrm{p}=0.425, \mathrm{p}=0.170)$ (Table IV).

\section{DISCUSSION}

In this study, $50 \%$ of tumor lesions located in pelvic ramus were malignant type. ${ }^{[22]}$ The diagnosis of ramus-localized lesions could vary from a nonspecific tumor-like lesion to an aggressive malignant tumor, and when a ramus-localized lesion was found, a wide range of differential diagnoses was required. In addition, the lesions were located more frequently in the pubic ramus and the lesions located in the ramus ischium had significantly higher risk of malignancy. Also, although there was no major vascular injury in surgery, inguinal swelling and diffuse edema were observed in some patients in the postoperative period, regardless of the tumor type being benign or malignant.

He et al. ${ }^{[4]}$ reported 4 cases with ischium location. Half of the cases were malignant in their study. There are also case reports of benign or malignant tumors located in the ramus in the literature. ${ }^{[8-20]}$ In the series of 24 tumor patients we reported, $50 \%$ of the tumors in the pelvic ramus were malignant.

In the literature, benign tumors such as chondromyxoid fibroma, intraosseous schwannoma, extracranial meningioma, $\mathrm{ABC}$, simple bone cyst, GCT, and OC localized to the pelvic ramus have been reported..$^{[2,4,11,15,16,18,19]}$ In the present study, there were also cases of enchondroma, fibrous dysplasia, $\mathrm{LCH}$, and ossifying fibroma that we had not seen before in the literature. In addition, tumor-like lesions such as insufficiency fractures, brown tumors, and synchondrosis have been reported in the literature..$^{[5-7]}$ In this study, we found that nonspecific fractures and some nonspecific lesions (eight cases) could give tumor-like clinical and radiological findings and we could diagnose them by histopathological examination. In addition, ramus involvement of malignant tumors such as CS, Bartholin gland carcinoma, and leiomyosarcoma has been reported in the literature. ${ }^{[3,4,8,20,23]}$ The most common malignant tumor in the present series was CS. We also found adrenal cortical tumor metastasis, unknown primary metastasis, and lymphoma tumors that, to our knowledge, had not been reported in the literature.

It is known that pubic ramus is one of the locations where insufficiency fractures like to settle. ${ }^{[24]}$ In recent years, case reports of benign or malignant tumors and tumor-like lesions located in the ramus ischium or pubic ramus have been reported. ${ }^{[2-20]}$ In this study, which included 31 cases, the statistical analysis of the data found that the lesions were located more frequently in the pubic ramus, and the lesions located in the ramus ischium were found to have significantly higher risk of malignancy than tumor-like lesions.

Pelvic ramus is located in the deep pelvic region and surgical approach to pelvic ramus is difficult due to the proximity of important neurovascular structures and urogenital structures and intraabdominal organs. The main structures at risk with tumors or dissection in this area include the superficial femoral vessels and femoral nerve. Complications such as scrotal herniation of the bladder and transient femoral nerve palsy have been reported in the literature after ramus-located tumor surgery. ${ }^{[3,4,9,21,25,26]}$ In the present study, complications of diffuse edema/swelling and wound healing problem were observed.

There were some limitations of this study. First was the study's retrospective design. In addition, although this study included a high number of 
patients compared to the literature, the number of cases was relatively low due to the fact that this region is a very rare tumor location. Therefore, the reliability of the rates was not high, requiring further multicenter studies with larger sample sizes.

In conclusion, pelvic ramus may have many different tumoral lesions. Half of the isolated tumors of the pelvic ramus are malignant. Slightly more than half of these lesions require surgical treatment regardless of the type. Pelvic ramus tumors tend to settle more frequently in the pubic ramus, whereas ischial ramus tumors are more likely to be malignant. In addition, the diagnosis of insufficiency fracture should be considered primarily in the pathological fractures of pubic ramus in females over 50 years of age. In postoperative follow-up of patients with pelvic ramus tumors, diffuse edema can be seen even if there is no intraoperative vascular damage.

\section{Declaration of conflicting interests}

The authors declared no conflicts of interest with respect to the authorship and/or publication of this article.

\section{Funding}

The authors received no financial support for the research and/or authorship of this article.

\section{REFERENCES}

1. Öztürk R, Arıkan ŞM, Bulut EK, Kekeç AF, Çelebi F, Güngör BŞ. Distribution and evaluation of bone and soft tissue tumors operated in a tertiary care center. Acta Orthop Traumatol Turc 2019;53:189-94.

2. Arıkan M, Toğral G, Yıldırım A, Aktaş E. Chondromyxoid fibroma of the pubic ramus: a case report and literature review. Acta Orthop Traumatol Turc 2016;50:115-9.

3. Ene R, Panti ZA, Nica M, Popa MG, Cîrstoiu MM, Munteanu $\mathrm{O}$, et al. Chondrosarcoma of the pelvis - case report. Rom J Morphol Embryol 2018;59:927-31.

4. He X, Hu YC, Yu XC, Yuan BB. Resection of inferior pubic ramus tumors through a femoribus internus-perineal approach. Orthop Surg 2014;6:65-8.

5. Schapira D, Militeanu D, Israel O, Scharf Y. Insufficiency fractures of the pubic ramus. Semin Arthritis Rheum 1996;25:373-82.

6. Takeshita T, Takeshita $\mathrm{K}$, Abe $\mathrm{S}$, Takami H, Imamura T, Furui S. Brown tumor with fluid-fluid levels in a patient with primary hyperparathyroidism: radiological findings. Radiat Med 2006;24:631-4.

7. Herneth AM, Trattnig S, Bader TR, Ba-Ssalamah A, Ponhold W, Wandl-Vergesslich K, et al. MR imaging of the ischiopubic synchondrosis. Magn Reson Imaging 2000;18:519-24.

8. Kilpatrick SE, Pike EJ, Ward WG, Pope TL. Dedifferentiated chondrosarcoma in patients with multiple osteochondromatosis: report of a case and review of the literature. Skeletal Radiol 1997;26:370-4.

9. von Rundstedt FC, Waldner M, Mathers MJ, Brandt AS,
Lazica D, Roth S. "Scrotal pouch"-scrotal herniation of bladder secondary to extensive bone resection due to chondrosarcoma: a simple and effective surgical treatment of urinary obstruction. Urology 2009;74:206-8.

10. Nystrom LM, DeYoung BR, Morcuende JA. Secondary chondrosarcoma of the pelvis arising from a solitary exostosis in an 11-year-old patient: a case report with 5-year follow-up. Iowa Orthop J 2013;33:213-6.

11. Khan AQ, Siddiqui YS, Parameshwar A, Anwar-Sherwani MK. Aneurysmal bone cyst of pubis. A rare presentation. Saudi Med J 2010;31:317-20.

12. Nayak A, Kulkarni S, Kulkarni A, Natesh K, Bami M. Aneurysmal bone cyst of the pubis: a case report. J Clin Diagn Res 2013;7:1740-2.

13. Rao A, Samant PD, Varshneya A. Aneurysmal bone cyst of pubic ramus: A rare entity. J Orthop Case Rep 2013;3:42-5.

14. Garnjobst W, Hopkins R. Aneurysmal bone cyst of pubis. Report of a case presenting as an abdominal mass. J Bone Joint Surg [Am] 1967;49:971-5.

15. Benazzo F, Marullo M, Rossi SM, Viola E. Giant intraosseous schwannoma of the ileopubic ramus. Orthopedics 2013;36:e982-5.

16. Herode P, Shroff A, Patel P, Aggarwal P, Mandlewala V. A rare case of pubic ramus osteochondroma. J Orthop Case Rep 2015;5:51-3.

17. Houghton MJ, Heiner JP, De Smet AA. Osteoma of the innominate bone with intraosseous and parosteal involvement. Skeletal Radiol 1995;24:455-7.

18. Makris V, Papavasiliou KA, Bobos M, Hytiroglou P, Kirkos JM, Kapetanos GA. Simultaneous existence of unicameral bone cysts involving the femur and ischium. Acta Orthop Traumatol Turc 2009;43:185-9.

19. Bokhari A, Hibshoosh H, Tiscornia-Wasserman PG. Cytomorphology of Recurrent Osseous Extracranial Meningioma of Right Pubic Ramus:: Report of a Case and Literature Review. Diagn Cytopathol 2016;44:618-22.

20. Sundaram M, Akduman I, White LM, McDonald DJ, Kandel R, Janney C. Primary leiomyosarcoma of bone. AJR Am J Roentgenol 1999;172:771-6.

21. Choong PFM. Pelvis, general considerations. In: Sim FH, Choong PFM, Weber KL editors. Orthopaedic Oncology and Complex Reconstructions. 1st ed. Philadelphia: Wolters Kluwer; 2011. p. 3-12

22. Atik OŞ. Is there something new and interesting in my article? Eklem Hastalik Cerrahisi 2019;30:69.

23. Nomura H, Nagashima M, Aoki Y, Takeshima N. Resection of the inferior pubic ramus to completely remove locally advance adenoid cystic carcinoma of Bartholin's gland. Gynecol Oncol 2017;147:723-4.

24. Ayanaoğlu T, Atik OŞ, Tokgöz N, Uçar M. Sacral and pubic insufficiency fractures due to bisphosphonate treatment. Eklem Hastalik Cerrahisi 2015;26:120-4.

25. Öztürk R. Kemik ve yumuşak doku Tümörleri. In: Atay T, editör. Ortopedi ve Spor Yaralanmaları Asistan Kitabı. 1. Baskı. Ankara: Derman Tibbi Yayıncılık; 2015. s. $635-704$

26. Abraham JA, Kenneally B, Amer K, Geller DS. Can Navigation-assisted Surgery Help Achieve Negative Margins in Resection of Pelvic and Sacral Tumors? Clin Orthop Relat Res 2018;476:499-508. 